HUMANASE SOCIAIS

V.8 • N.3 • 2020 • Fluxo Contínuo

ISSN Digital: 2316-3801

ISSN Impresso: 2316-3348

DOI: 10.17564/2316-3801.2020v8n3p93-100
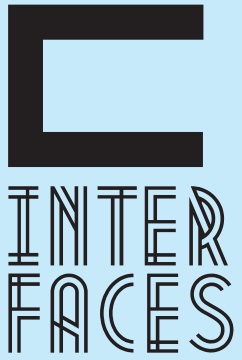

CIENTÍFICAS

\title{
O AFRONTAMENTO DE TÁSSIA REIS : NÃO TOLERAMOS MAIS O SEU XIU
}

\author{
TASSIA REIS'S AFFRONT: \\ WE NO LONGER TOLERATE YOUR SHUSH
}

\section{LA CONSECUENCIA DE TASIA REIS: NO TOLERAMOS TU XIU}

\section{PALAVRAS-CHAVE}

Feminismo Negro. Tássia Reis. Música Popular Brasileira. Vozes Negras. 


\section{ABSTRACT}

The protagonism of black women in art is still something to be studied and questioned. Music is an artistic language that offers us the means for a study of this nature and which can make a difference. This article intends to highlight these authorial voices full of subjectivity that dare to rebel in a plural but never democratic Brazilian popular music. In particular, for this study, we selected a young, black, suburban artist: Tássia Reis. With a recent but significant career, the artist, born on the outskirts of São Paulo is, in addition to composer, singer and owner of the clothing brand "Xiu" (which can be translated as "Shush"), a black feminist activist who recognizes that there are several ways to silence the memories of a people, to keep them underground, enclosed bordering total oblivion, silencing them once and for all. Thus, to use as theoretical basis the concept of intersectionality of Crenhsaw (2015), of place of speech of Djamila Ribeiro (2017), of plural voices of Adriana Cavarero (2011) is to understand how this obliteration reconfigures itself over the decades and along the black artist's market. After all, the personal is political. This is what is intended with the present work.

\section{KEYWORDS}

Black Feminism. Tássia Reis. Brazilian Popular Music. Black Voices.

\section{RESUMEN}

El papel de las mujeres negras en el arte todavía es algo para ser estudiado y cuestionado. La música es un lenguaje artístico que nos ofrece medios para un estudio de esta naturaleza que puede marcar la diferencia. Este artículo pretende resaltar estas voces autoritarias cargadas de subjetividad que se atreven a rebelarse en una música brasileña, popular y plural, pero nunca democrática. En particular, en este estudio, seleccionamos a una joven artista negra y de la periferia, Tássia Reis. Con una trayectoria reciente, pero bastante impresionante, la artista, nació en las afueras de São Paulo. Además de compositora, cantante y propietaria de la marca de ropa «Xiu», es una activista feminista, negra, que reconoce que hay varias maneras de silenciar los recuerdos de un pueblo, mantenerlos bajo tierra, enmarcados en el olvido total, silenciarlos de una vez por todas. De esta manera, utilizar como base teórica el concepto de Interseccionalidad de Crenhsaw (2015), el Lugar del discurso de Djamila Ribeiro (2017) y Voces plurales de Adriana Cavarero (2011) es entender cómo este desaparecimiento se está reconfigurando a lo largo de las décadas y del mercado de la artista negra. Después de todo, la gente es política. Esto es lo que se pretende con el presente trabajo.

\section{PALABRAS CLAVE}

Feminismo negro; Tássia Reis; Musica Popular Brasileña; Voces negras 


\section{BREVE BIO}

Tássia dos Reis Santos, conhecida como Tássia Reis, nascida em 1989 na cidade de Jacareí, situada na região do Vale da Paraíba no estado de São Paulo, é uma das vozes de destaque do cenário contemporâneo independente da música popular brasileira. É a terceira filha de um casal de trabalhadores nativos de bairros periféricos - Benedito e Myriam -, integrantes de escolas de samba rivais, que a fizeram conviver desde cedo com os movimentos do samba paulista. Sua trajetória artística é marcada por uma história pessoal de lutas e transgressões.

Tássia Reis é formada em Tecnologia do Desing em São Paulo, iniciou seu contato com o Hip Hop por meio da dança aos quatorze anos de idade; traz em sua estética musical e visual uma afirmação identitária que reflete a descolonização do pensamento, o Afrofuturismo, se "considerando uma feminista negra interseccional". Conectada com o discurso de autoras negras que lhe inspiram, dialoga, por meio dos seus versos, com este lugar de fala que representa a expansão, reconfiguração e urgência do feminismo negro de sua geração.

A voz da ativista não traz somente uma disfonia em relação à história dominante do feminismo, mas também a urgência por existir e a importância de evidenciar que mulheres negras historicamente estavam produzindo insurgências contra o modelo dominante e promovendo disputas de narrativas. Nesse sentido, pensar a partir de novas premissas é necessário para se desestabilizar verdades. (RIBEIRO, 2017, p. 26).

A voz de Tássia, musicalmente potente e harmoniosa, traz em seu discurso o teor disfônico, uma vez que não corresponde aos padrões das indústrias fonográficas dominantes; sua voz projeta a fala de uma coletividade que habita sobretudo os centros periféricos; desde sua adolescência foi por meio de um grupo feminino de street dance e a convivência com o Hip Hop que Tássia Reis imprime em sua voz e estilo o reflexo das realidades dos muitos Brasis existentes; foi ali, naquele espaço artístico engajado que pôde iniciar sua afirmação política no mundo, sendo uma porta voz efusiva das desigualdades de gênero, de classes e étnicas; sua arte afirma a importância do empoderamento, da auto-afirmação e da aceitação da subjetividade do corpo, quebrando os padrões estéticos e hegemônicos vigentes na sociedade brasileira, ainda dominada pelo pensamento patriarcal.

Tássia traçou caminhos para desestabilizar as verdades impostas pelos sistemas e para, ao seu modo, fazer ecoar sua condição de artista negra periférica que se encontra numa encruzilhada de opressões. No entanto, essa encruzilhada é um território cuja “intertextualidade não é apenas o texto escrito, mas também a presença de uma voz que ‘fura’ o discurso e atualiza a obra. Dessa forma, o texto é o mesmo, mas a obra e a voz não" (ZUMTHOR, 2007, on-line). Tássia representa esta geração que não manda recado. Sua voz é um ruído que, ancorada no corpo, é única, especial.

Em 2010, numa paticipação no show do rapper Kamal, Tássia inicia a ascenção de suas rimas nos microfones. Até então, brincava com suas composições no freestyle, despretenciosamente. Mas, com o surgimento de novos encontros e possibilidades, começou a se dedicar ao Rap. A gravação de seu primeiro single Meu rapjazz em 2013 e suas prolíficas produções musicais a coloca na cena nacional 
como uma importante referência do midstream da indústria fonográfica brasileira e uma das mais requisitadas artistas independentes da contemporaneidade.

\section{DAS RUAS AS PLATAFORMAS DIGITAIS - PERCURSO MUSICAL}

O percurso de Tássia Reis representa, afirma e em alguns pontos precede, o que atualmente denomina-se música midstream; esta recente nomenclatura do movimento fonográfico contempla os trabalhos independentes que não são considerados parte do mainstream nem do underground musical; é um caminho intermediário no qual artistas independentes consolidam suas carreiras frente à democratização do acesso de suas produções, utilizando as redes sociais.

$\mathrm{O}$ artista do midstream - que em alguns casos anteriormente sentia-se representado pela categoria indiev, ou seja, não vinculado a grandes gravadoras - adquire atualmente uma liberdade ainda maior quanto à estética de sua arte e a possibilidade de consolidação de seu público diante da atual era virtual.

Assim, pode-se então melhor compreender que para uma artista como Tássia Reis - que, em suas palavras, valoriza "[...] a estética no sentido plástico das coisas, de transmitir mensagens [...]" -, caminhar com maior liberdade, empreendendo e direcionando suas produções artísticas acaba sendo uma necessidade de sua expressão musical.

O canto de Tássia Reis - com seu timbre e discurso potentes e uma exuberante estética - imprime a pluralidade e complexidade de um percurso autoral autêntico, que transita em rede; é muito por meio da arte, logo da música, que acontece a propagação e democratização das diferentes realidades e suas formas de produções.

Curioso notar que sua música não enfatiza necessariamente a linguagem rítmica brasileira - não ouve-se por exemplo, em grande destaque, os elementos e células das matrizes afrobrasileiras - e traz uma concepção sonora mais ligada aos conceitos musicais norte-americanos. Entretanto, em sua música, não deixa de sentir, a forte presença da ancestralidade marcada por novas configurações e tempos, uma das característica do afrofuturismo, que dialoga atualmente com milhares de brasileiro(a)s.

De fato, desde o final dos anos 1960 que se assiste, no Brasil, uma forte conexão musical com os movimentos afro-americanos. Se grandes cantoras de Jazz como Ella Fitzgerald, Sarah Vaughan, Billie Holyday, o funk de James Brown, a guitarra de Jimi Hendrix, o canto de Chaka Khan e outros da gravadora Motown inspiraram artistas brasileiros de outras gerações, atualmente são os artistas da cena Hip Hop norte-americana como Snoop Dogg, Kanye West, Missy Eliot e tanto(a)s outro(a)s que tornaram-se importantes referências da música urbana brasileira, sobretudo periférica.

É como se alguns elementos da força da expressividade de Tássia Reis fosse centrípeta, ou seja, de fora pra dentro, o que é legitimado pelo acesso midiático virtual globalizado de sua geração. Citando a musicóloga Adriana Piccolo (2006, p. 13) pode-se enxergar em Tássia “[] o canto como representação cultural e identitária, incluindo questões como tradição e reinvenção, identidade e diferença, nacionalismo e globalização”.

Influenciada então por diversas vertentes da música afrodiaspórica - R\&B, Jazz, Rap, Samba, dentre outras -, a música de Tássia é urbana e inquieta. Com dois EP gravados, Tássia Reis (2014), 
Outra esfera (2016) e seu recente primeiro álbum Próspera (2019), a cantora e compositora leonina sintoniza e afina seus versos para, sobretudo, fortalecer a luta no combate à invisibilidade e discriminação das mulheres negras.

\author{
Quer saber \\ Que me incomoda, sincero \\ É ver que pra nós a chance nunca sai do zero \\ Que, se eu me destacar, é pura sorte, jão \\ Se eu fugir da pobreza não escapo da depressão, não \\ Num quadro triste, realista \\ Numa sociedade machista \\ As oportunidades são racistas \\ São dois pontos a menos pra mim \\ É difícil jogar \\ Quando as regras servem pra decretar o meu fim \\ (Da lama/Afrontamento)
}

Afrontamento, música que constitui o EP Outra esfera, pode ser escutada como um diálogo que evoca a questão da interseccionalidade das mulheres pretas. Nessa música Tássia utiliza sua voz para fortalecer a luta antirracista; com harmonia e melodia minimalistas, num invólucro eletrônico afrofuturista, é o verbo quem lidera a canção; a música assume um lugar de protesto, como meio de informação, buscando a expansão da consciência e se unindo ao combate ao racismo. Citando Grada Kilomba (2019, p. 4):

0 ato de falar é como uma negociação entre quem fala e quem escuta, isto é, entre os sujeitos que falam e seus/suas ouvintes. Ouvir é, nesse sentido, o ato de autorização em direção à/ao falante. Alguém pode falar (somente) quando sua voz é ouvida.

O Rap representa na atualidade uma das principais linguagens de reivindicação do povo preto. Ocupa um lugar como o do samba, reunindo e conectando as pessoas, difundindo a realidade dos guetos e aspirando mudanças sociais. Sabe-se que é preciso que muito(a)s brasileiro(a)s se conscientizem dos seus privilégios, que estejam cientes, por exemplo, sobre o ainda desconhecido conceito da Branquitude e que possam agir, quebrando antigos padrões para a construção identitária de sociedades mais justas e equilibradas.

Se a Branquitude denuncia o monoculturalismo e reconhece a necessidade e urgência de reconhecer os privilégios brancos que, também na arte, impediram a ascenção das vozes negras, será necessário que numa maior escala possa-se agir para a composição de novas configurações artísticas que dêem conta da racialização do branco, não o tomando como padrão, buscando aumentar e evidenciar as vozes negras e indígenas, há muitos anos caladas e invisíveis nas mídias e consequentemente para boa parte das sociedades brasileiras.

Se por um lado, sabe-se da diversidade da cultura brasileira, sabe-se também da necessidade de escuta das diferentes diaspóras existentes nos solos brasileiros e de uma maior representatividade 
delas no cenário cultural. Ouvir Tássia Reis é um caminho para se aproximar de muitas realidades que clamam por esta equidade.

Tássia colaborou/colabora com importantes nomes do Rap, MC, fez/faz parte de alguns coletivos como Rimas e Melodias, Salada de Frutas (evento em colaboração com outros artistas como Liniker, as Banda Caramelows e As Bahias e a Cozinha Mineira). Com sua arte engajada e em ebulição, rédeas entre as mãos e planos sem fim, o sucesso de Tássia Reis abre portas para dar continuidade aos sonhos de uma mulher que não poupou esforços para a construção de uma ambiciosa carreira artística.

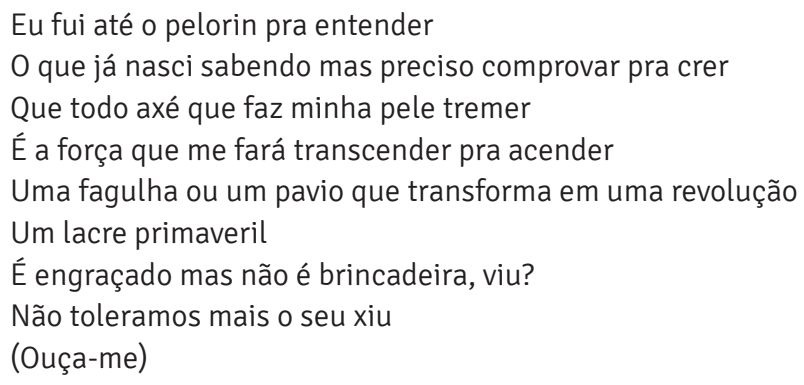

\section{CONCLUINDO...}

Esta filha de Oyá - orixá dos Nove mundos, que tem como uma de suas características ser potência na intermedição dos mundos, das dimensões; orixá ativa que impulsiona sua vida com coragem e audácia -, segue firme e determinada em sua arte, traçando seu trilhar com bravura. Recentemente conquistou um novo sucesso empresarial, realizando um antigo sonho: a criação de sua marca de roupa "Xiu”, inspirada no empoderamento das minorias.

Tássia Reis é uma voz que, para além de representar resistência e musicalidade, faz ecoar cores e criatividade, mostrando para quem acessa sua arte, a importância de apostar na afirmação da singularidade e da subjetividade, sem esquecer a coletividade.

\section{REFERÊNCIAS}

ALCANTARA, Fábio. 'Nossa história precisa ser contada por nós mesmos', diz Tássia Reis, que lança grife XIU! Vírgula, 15 out. 2017. Disponível em: http://www.virgula.com.br/musica/nossa-historiaprecisa-ser-contada-por-nos-mesmos-diz-tassia-reis-que-lanca-marca-de-roupas-xiu/. Acesso em: 13 jun. 2019.

ENTREVISTA \#19 Tássia Reis - Afronta (Face it!). TV preta, 5 mar. 2018. Disponível em: https://www. youtube.com/watch?v=DRB3I6BITTQ. Acesso em: 12 jun. 2019. 
ENTREVISTA Tássia Reis, rainha. Trip TV, 10 mar. 2017. Disponível em : https://www.youtube.com/ watch?v=PcESoqFbEto. Acesso em: 13 jun. 2019.

ENTREVISTA. Centro da Terra, set. 2018. Disponível em: http://centrodaterra.org.br/tassia-reis. Acesso em: 12 jun. 2019.

KILOMBA, Grada. Memórias da plantação: episódios de racismo cotidiano. Rio de Janeiro: Cobogó, 2019.

MOREIRA, Larissa Ibumi. Vozes transcendentes: os novos gêneros na música brasileira. São Paulo: Hoo Editora, 2018.

NOGUEIRA, Mariana. Tassia Reis sobre empoderamento: você não pode dar talento, mas pode gerar oportunidade. Glamour, 9 nov. 2017. Disponível em: https://revistaglamour.globo.com/Lifestyle/ Must-Share/noticia/2017/11/tassia-reis-sobre-empoderamento-voce-nao-pode-dar-talento-maspode-gerar-oportunidade.html. Acesso em: 13 jun. 2019.

PICOLLO, Adriana Noronha. $O$ canto popular brasileiro: uma análise acústica e interpretativa. Rio de Janeiro: UFRJ, 2006.

PRISCO, Luiz. O que é midstream: Entenda o novo conceito da indústria musical. Metrópoles, 10 jun. 2019. Disponível em : https://www.metropoles.com/entretenimento/musica/o-que-emidstream-entenda-o-novo-conceito-da-industria-musical. Acesso em: 13 jun. 2019.

REIS, Tássia. Lojas Xiu. Disponível em: http://www.lojaxiu.com.br/. Acesso em: 16 jun. 2019.

RIBEIRO, Djamila. O que é lugar de fala? Belo Horizonte: Letramento justificando, 2017.

ZUMTHOR, Paul. Uma fronteira tênue entre a voz e a letra. Publicado por Lilian Silva Salles, 15/12/2007. Disponível em: http://www.webartigos.com. Acesso em: 12 jun. 2019. 
1 Pós-doutora pela Universidade de Lisboa ; Professora associada II do Instituto de Humanidades Artes e Ciências prof. Milton Santos-IHAC/UFBA; Professora permanente do Programa multidisciplinar de Pós-graduação em Cultura e Sociedade, do Mestrado profissional em Artes - PROFARTES; Atualmente está em estágio pós-doutoral no Instituto de Artes na UNICAMP - IAR. E-mail: marilda62@gmail.com

2 Graduada no Bacharelado Interdisciplinar em Artes do IHAC-UFBA; Bolsista de Iniciação Científica, PIBIC 20182019; Cantora, compositora e produtora musical.

E-mail: monica.mfreiere@yahoo.com 